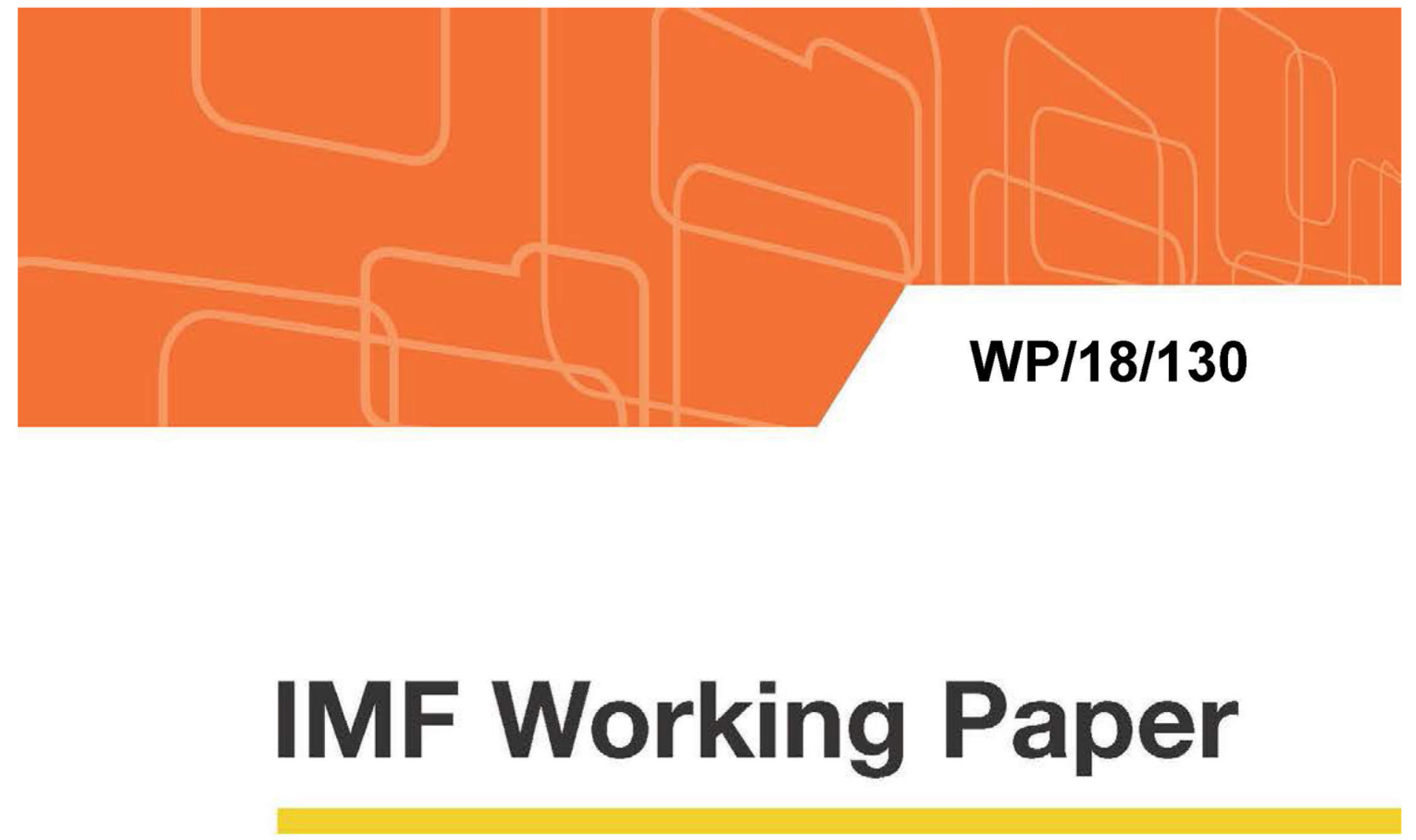

\title{
Progressive Taxation of Extractive Resources as Second-Best Optimal Policy
}

by Jean-François Wen

IMF Working Papers describe research in progress by the author(s) and are published to elicit comments and to encourage debate. The views expressed in IMF Working Papers are those of the author(s) and do not necessarily represent the views of the IMF, its Executive Board, or IMF management.

$$
\text { I N T ER N A T I O N A L M O N E T A R Y F U N D }
$$




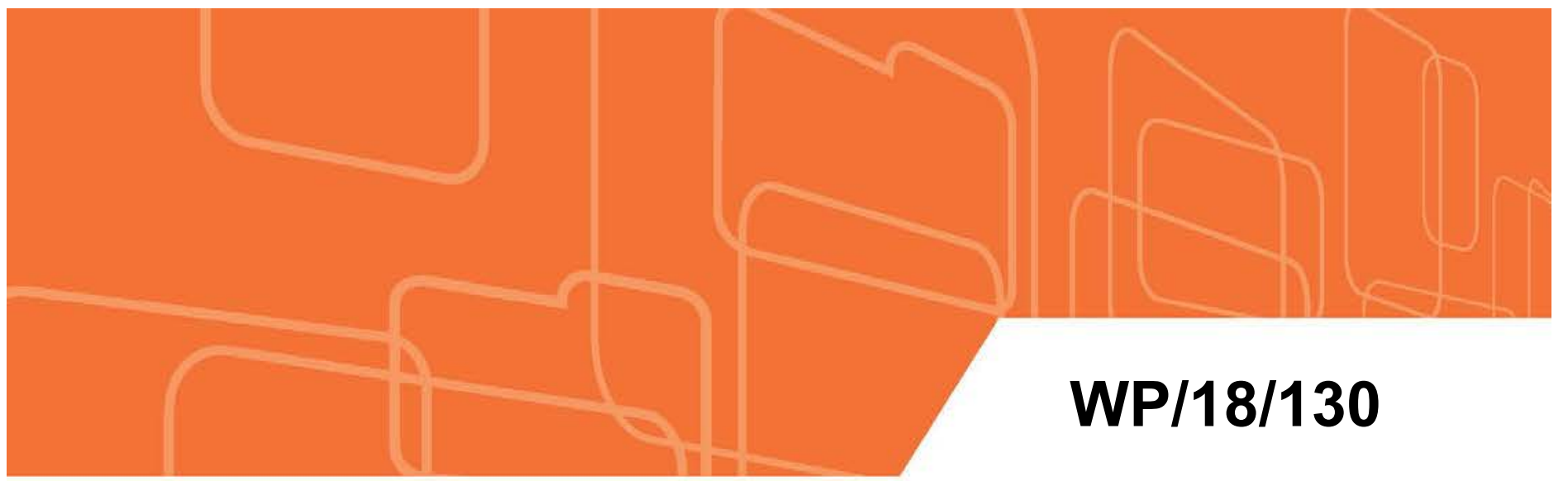

\section{IMF Working Paper}

\section{Progressive Taxation of Extractive Resources as Second-Best Optimal Policy}

by Jean-François Wen

IMF Working Papers describe research in progress by the author(s) and are published to elicit comments and to encourage debate. The views expressed in IMF Working Papers are those of the author(s) and do not necessarily represent the views of the IMF, its Executive Board, or IMF management. 


\title{
IMF Working Paper
}

Fiscal Affairs Department

\section{Progressive Taxation of Extractive Resources as Second-Best Optimal Policy Prepared by Jean-François Wen}

\author{
Authorized for distribution by Ruud de Mooij
}

June 2018

\section{IMF Working Papers describe research in progress by the author(s) and are published to elicit comments and to encourage debate. The views expressed in IMF Working Papers are those of the author(s) and do not necessarily represent the views of the IMF, its Executive Board, or IMF management.}

\begin{abstract}
The paper provides a critical review of the literature on the concept of progressivity in the taxation of petroleum and mineral resources and offers a fresh perspective on its purpose and measurement. Regressive taxes, such as royalties, exist to satisfy policy objectives other than revenue maximization, such as achieving early revenues, while rent-based or profit-sensitive fiscal instruments must be designed with progressive marginal rates to maximize government revenues. Hence, the emphasis should be placed on tax rate progression of the direct taxation of profit or rent, rather than progressivity in the overall government take. However, as regressive taxes, by their very nature, tend to be distortionary, the optimal degree of progression in the rent- or profit-tax rates must take these distortions into account. The central ideas are illustrated with a simple analytical model in which a second-best optimal tax rate schedule on profit is characterized in the presence of the tax distortions caused by the regressive taxes. Some practical implications of the analysis are discussed.
\end{abstract}

JEL Classification Numbers: H21, H25, Q35

Keywords: Minerals, petroleum, rent tax, average effective tax rate, second-best optimality Author's E-Mail Address: JWen@imf.org 


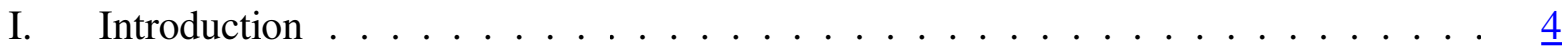

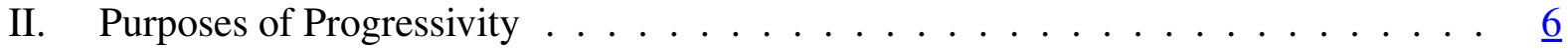

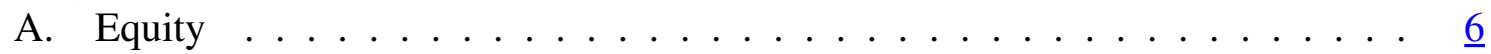

B. Flexibility and Stability ............... $\ldots$

III. A Different Perspective ..................... . $\underline{9}$

IV. Decomposing Non-Neutral Taxes into a Rent Tax and a Factor Tax . . . . . . . . 12

A. $\operatorname{Rent} \operatorname{Tax} \ldots \ldots \ldots \ldots \ldots \ldots \ldots \ldots$

B. Factor $\operatorname{Tax} \ldots \ldots \ldots \ldots \ldots \ldots \ldots$

C. Royalties ....................... . . . . 15

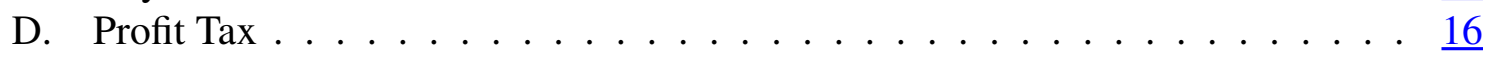

V. Progressive Profit Tax Rates . . . . . . . . . . . . . . . . . . 17

A. Royalty and Profit Tax . . . . . . . . . . . . . . . . . . . . . . . . . . . .

B. Firm's Behavior with Distortionary Taxes . . . . . . . . . . . . . $\underline{18}$

C. Progressivity of the Profit Tax . . . . . . . . . . . . . . . . 19

D. Binding Constraint: $T(p)=V(p) \ldots \ldots \ldots \ldots \ldots$

E. Non-Binding Constraint: $T(p)<V(p) \ldots \ldots \ldots \ldots \underline{23}$

F. Implications for Average Tax Rate Progressivity . . . . . . . . . . . . 26

VI. Practical Implications $\ldots \ldots \ldots \ldots$

VII. Conclusions ......................... . .

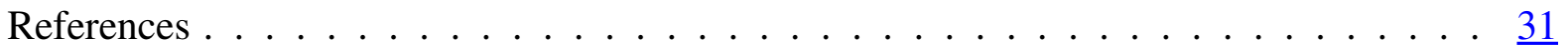




\section{INTRODUCTION}

The principle that fiscal regimes for petroleum and minerals should exhibit 'progressivity' is commonly advocated (see, e.g., Daniel, 2010: 190). ${ }^{1}$ Progressivity, in the usual sense of the literature, refers to a rising government share of the net cash flows of a project- the so-called government take - as the value of the resource increases. Boadway and Keen (2010:38) define progressivity more formally as subjecting "cumulative rents $V$ to some tax $T(V)$ that is progressive in the sense that the average tax rate $T(V) / V$ increases with $V . " 2$ These definitions underscore the use of an Average Effective Tax Rate (AETR) as the measure of a project's tax burden. Keen et al. (2014: 20) define the AETR as "the ratio of the present value of government receipts over the lifetime of a project to the present value of pre-tax cash flows, both calculated at some common discount rate." The degree of progressivity can be gauged by plotting the AETR against different levels of the pre-tax internal rate of return (IRR) or the Net Present Value (NPV) of a project or against the price of the resource. A rising AETR profile is synonymous with a progressive tax regime. ${ }^{3}$ However, the arguments for why progressivity is a desirable feature of fiscal regimes are rather unclear and uncompelling. This paper provides a critical review of the literature on the progressive taxation of petroleum and minerals and offers a different perspective on its purpose and measurement.

The main insights are as follows. Regressive taxes (the opposite of progressive), such as royalties, signature bonuses, and land rental fees, exist to satisfy various government objectives other than revenue maximization. ${ }^{4}$ Such auxilliary objectives of fiscal regimes include generating tax revenues early in a project's life cycle and ensuring revenues for the government even in the face of weakening economic conditions. Then, given the existence of regressive elements in the fiscal regime, the government's primary objective of revenue maximization requires marginal tax rate progressivity in the design of its profit-sensitive fiscal instruments. In this way, the progressive tax instruments enable governments to capture the rent 'left on

\footnotetext{
${ }^{1}$ Progressivity is one of the guiding principles of fiscal regime design in the IMF's FARI model. See Luca and Mesa Puso (2016)

${ }^{2}$ The economic rent generated by a natural resource project is the pre-tax difference between the present value of revenues and the present value of costs incurred in the project. Note that the costs of a project include socalled normal profit, which is the minimum amount of compensation required by the investors to justify their equity stake. The importance of rent for tax policy resides in the fact that directly taxing it avoids creating incentives that distort the behavior of the project's private sector stakeholders. In particular, the capital investment decisions and ongoing operations would in theory be unaffected, if the tax base consists exclusively of economic rent. In other words, a tax levied solely on rent is a neutral tax. This implies that a project operator's choices will serve to maximize the rent, thereby providing the resource owner, i.e., the government, with a larger collection of revenues than it can achieve with other forms of resource taxation, such as royalties and corporate income tax.

${ }^{3}$ Another measure of progressivity often used in IMF Technical Assistance reports is the profile of government revenue as a share of the quasi-rent (i.e., pre-tax revenues net of operating costs) — called the share of "total benefits" in FARI terminology.

${ }^{4}$ Royalties are typically paid as percentage of gross revenues, rather than as a percentage of profit.
} 
the table' by the regressive instruments. ${ }^{5}$ However, by their very nature, regressive taxes tend to be distortionary taxes, and vice versa. ${ }^{6}$ In the presence of such distortions, profit-sensitive taxes themselves, even a direct tax on economic rent, cease to be neutral. As a result, the optimal degree of marginal tax rate progression of the profit-sensitive taxes must be considered in a second-best policy environment. The emphasis of tax policy evaluation is thereby shifted from achieving progressivity in the overall government take to setting an optimal degree of marginal tax rate progression in the direct taxation of profit or rent.

One result of the analysis is that, the higher the royalty rate, the more progressive the profitsensitive tax rate schedule should be, although the general level of the tax rates on profit must be lowered to accommodate a high royalty rate. The overall effect of a royalty, together with an optimal progressive rate schedule, on the shape of the AETR graph is generally unclear and not necessarily expected to be progressive. There are several other practical implications of the analysis. The first is that it is useful to plot separately the AETR for the regressive and the progressive tax instruments to better visualize the performance of the profit-sensitive tax instruments for maximizing tax revenue, taken as a given the regressive instruments, whose existence is, presumably, not revenue maximization. Moreover, a measure of the performance of the profit-sensitive tax rates is the 'buoyancy' or elasticity of total government take with respect to the changes in the economic rent generated by a project. If the elasticity is close to one, it means that, as the rent increases, say, due to an increase in the price of the resource, the progressivity of the profit-sensitive instruments fully offsets the regressive elements of the fiscal regime, and any windfall rent is captured as government revenue. In addition, from the perspective of this paper, since royalties exist mainly to ensure early government revenues, the royalties should be creditable (with an uplift for the time value of money) against profit taxes (or rent taxes) in the post-payback period. In this way, governments can achieve early revenues without compromising the objective of revenue maximization and, hence, the rate schedule for the profit taxes can be relatively flat, minimizing tax distortions. The central ideas are formalized and illustrated with a simple model in which a second-best optimal tax on rent is derived in the presence of other tax distortions. The theoretical model omits many real-world features of the extractive industries, but has the virtue of clarifying and illustrating the central ideas precisely.

The paper is organized as follows. Section 2 reviews the literature on the purposes of progressivity. Section 3 critiques the literature and offers a different perspective on progressivity. Section 4 introduces a simple analytical model and uses it to establish the equivalence between distortionary and regressive tax instruments. Section 5 uses the theoretical model to

\footnotetext{
${ }^{5}$ The expression 'marginal tax rate progressivity' is used in this paper to refer to a sliding scale for the tax rate. For example, the tax rate could be increasing with the price of the resource, or increasing with a proxy for profitability, such as an R-factor or the after-tax internal rate of return. The sliding scale tax rate could apply to the whole of the firm's profit or to the marginal tranche of profit. The term 'profit-sensitive' indicates tax bases that allow deductions for a significant part of the costs of resource extraction. The most extreme or idealized form of a profit-sensitive tax is one that is levied directly on economic rent.

${ }^{6}$ An exception to this statement is a pure resource rent tax (with no other fiscal instruments) that is designed with a regressive tax rate schedule. In that case, the fiscal regime can be regressive but neutral. However, one is hard-pressed to conceive of a tax for which the converse statement can fail to hold.
} 
examine the second-best optimal degree of tax progressivity. Section 6 discusses some of the practical implications of the results of the theoretical analysis. Conclusions are in Section 7.

\section{Purposes of Progressivity}

Boadway and Keen (2010) note that a neutral progressive tax could be achieved (at least under risk neutrality) with the progressive variant of the Resource Rent Tax (RRT), as proposed by Garnaut and Clunies Ross (1983). However, Land (2010: 251) observes that, "In practice, no host government has relied on resource rent taxes on their own. Instead, resource rent taxes are combined with other taxes and charges. Thus, in a royalty/tax regime, a resource rent tax is typically combined with royalty and corporation tax." The onus is then typically placed on achieving progressivity with the full package of fiscal instruments. A typical statement to this effect is: "The practice has been to combine progressive taxes with these other taxes that provide revenue in the early stage. With such hybrid systems progressivity can still be achieved overall by offsetting the regressive elements through the introduction of sliding scale for example with royalties.'(Emphasis added.) ${ }^{7}$ Similarly, Calder (2010: 323) suggests, "The desired objectives [including progressivity] can generally best be fulfilled by a mainlyprofit based tax regime incorporating an effective rent capture mechanism, with a limited role for royalties or cost recovery limits to reduce government risk and provide assurance of early revenues."

But what is the underlying reason for recommending a progressive tax regime for natural resources? Doubts have been raised, for example, by Boadway and Keen (2010: 38): "While there is no difficulty of principle in levying a progressive rent tax, it is not obvious why one might want to do so." The most commonly cited reasons for progressivity are 'equity' and 'flexibility' or 'stability.'

\section{A. Equity}

An analogy is sometimes made between progressive resource taxes and progressive personal income taxes. On the surface, the idea of an increasing profile for government take parallels the most commonly used definition of tax progressivity in personal income taxation, which is that a taxpayer's average tax rate - i.e., a person's tax bill as a share of income - should be an increasing function of personal income. Progressive personal income taxes are conceptually tied to notions of an equitable distribution of income or inequality aversion. The equity argument is invoked in the resource tax literature. For instance, Hann and Rowland (1986: 2) argue that, "a progressive tax system would also adhere to the equity principle that 'the rich should pay more.' Nakhle (2004: 23) discusses the vertical equity principle of fairness in the context of resource taxation, saying, "A progressive tax is more likely to satisfy this criterion.

\footnotetext{
${ }^{7}$ Lad-Ojomo (2008/2009).
} 
Firms that exploit more valuable resources have a greater ability to pay and so their tax liabilities can be greater."

The analogy between a progressive profile for the AETR in natural resource taxation and progressivity in personal income taxes is tenuous. First of all, the investors in a resource project are more than likely to be foreign shareholders. Hence, the government would have no equity reason to provide tax relief on projects yielding only modest rent. Furthermore, "a claim to high rents is neither necessary nor sufficient for high income at a personal level" (Boadway and Keen, 2010: 38). Finally, a tax on corporate profits may be shifted onto the consumers of natural resource products or on to the workers in the domestic resource extraction industry through equilibrium changes in market prices or wages. Thus the equity argument for progressive personal income taxation does not readily extend to natural resource taxation. The only role for equity in this context is the fact that, as owner of the resource, a government is entitled to maximize its return on behalf of its citizenry. But maximizing the return depends on the 'height' of the AETR curve, not on its 'slope.'

\section{B. Flexibility and Stability}

Ensuring the stability of a tax regime is the most commonly cited reason for progressively taxing resource rents. Stability means that the tax regime will not be subjected to political or bureaucratic pressures for renegotiation, when the economic conditions of a natural resource project change. Stability is achieved by making the regime flexible, in the sense that the tax rates adjust automatically with changes in circumstances, such as increases or decreases in the resource price.

Hogan and Goldsworthy (2010: 133) describe flexibility in rent collection as "the capacity of fiscal instruments to collect a reasonable share of the resource rent over time under a range of future market outcomes" and they note that, "Rent and profit-based taxes and state equity instruments rank more highly under this criterion since the government take tends to vary with project profitability." Similarly, Land (2010: 245) states that, "[T]he tax system should be designed with the flexibility to extract the different rents actually generated by deposits under dynamic conditions of price and cost on an ex post basis. This requires, in any individual case, that the higher the profitability of resource extraction, the greater the share of total benefits that accrues to the host country. Where this positive correlation exists, the fiscal regime is said to be progressive."

Daniel et al. (2010: 193) note that "[T]he adaptability of the system will also influence investor perceptions of risk. A system that responds flexibly to changes in circumstances may be perceived as more stable." They observe further that, "Adaptability can be measured by indicators of progressivity." The idea is echoed in Hann and Rowland (1986: 3): "if the tax system is progressive, then it is more likely to be stable." Boadway and Keen (2010) provide a formal model to show how a progressive system can foster stability by mitigating populist

demands for expropriation when resource prices are high. Similarly, in his comments on why Norway has 'tailored' — i.e., revised — its petroleum tax system over the years, Osmund- 
sen (2010: 438) writes, "Another reason for choosing a tailored tax system is the political constraints imposed by voter dislike of large profits and high dividends at private petroleum companies." He argues that a purpose of progressivity is to reduce the need for tailoring: "The problem is that tax changes are made on an ad hoc basis. If progressivity is an important goal for the government, it would be better from that perspective to construct a clearly defined and stable progressive tax system." 8

The flexibility/stability argument for tax progressivity appears sensible and grounded in experience. But, on second thought, the notion that flexibility corresponds to progressivity of the overall tax regime makes little sense theoretically. Surely, political stability and resilience to calls for renegotiation are more likely to be determined by whether the tax system captures a large portion of the rent, not whether it is progressive per se. If an oil field has the potential to deliver, say, a 70 percent government take, it is surely of little relevance that the tax regime captures 40 percent when the price of oil is modest and 50 percent when the price of oil is high. Citizens would be right in rebuking the government for the policy.

Upon closer examination, the argument for flexibility appears not really to be a call for the progressive taxation of rents, but is rather an admonishment for the excessive use of distortionary taxes, such as royalties. ${ }^{9}$ Daniel et al. (2010: 214) summarize the conventional wisdom in saying, "A more progressive regime gives some relief to investors for projects with low rates of return, while allowing the government to increase its share of revenue when the investment is highly profitable. Thus, a more progressive regime could attract investment for marginal projects (increasing government revenue over time), just as a heavy early fiscal burden on a project could deter investment altogether." (Emphasis added.) While the regressivity of certain widely used fiscal instruments provides a justification for having progressive components in the tax system, it is not a persuasive argument for progressivity in the overall proportion of rent collected by the government from a given resource project. In other words, disapproval of regressive fiscal regimes is not logically equivalent to support for progressive ones. A tax regime with both progressive and regressive elements may still result in a constant value of the overall government take-i.e., government revenues that are proportional to the size of the economic rent.

These observations suggest an alternative perspective on progressive natural resource taxation. Regressive taxes serve policy objectives other than tax revenue maximization. In this context, progressivity is an appeal to the government to ensure that profit-sensitive elements of the fiscal package are designed to capture the rent left over by the regressive taxes. The comment of Hann and Rowland (1986: 2) on reforming the UK North Sea regime is suggestive: "if the tax is progressive then the detrimental impact of other imperfections in the tax system will not be magnified. For example, if the tax base includes part of normal profits then

\footnotetext{
${ }^{8}$ The stability arguments suggest a relatively short time frame for measuring progressivity based on annual corporate income or post-development quasi-rents.

${ }^{9}$ The argument does not appear to apply to the political economy model of Boadway and Keen (2010), where there are no tax instruments other than the tax on rent. The problem remedied by progressive taxation in their model is an inability of governments to commit future governments to a given tax regime.
} 
there will be a reduction in marginal field profitability. If the tax system is not progressive then this reduction may be severe and development decisions on many fields may be jeopardised." It is, however, a measure of the confusion in the literature that Hann and Rowland's observation leads them to the conclusion that the petroleum tax system as a whole should be progressive, rather than, for example, insisting that only the Petroleum Revenue Tax be progressive by introducing increasing marginal tax rates. In fact, Hann and Rowland argue (p. 3) that the UK should opt for a progressive Resource Rent Tax to replace both the Petroleum Revenue Tax and the Corporate Income Tax on North Sea projects, saying, "[A] beneficial implication of a progressive tax system is that price signals to the developers of marginal fields will not be dampened." They state further (p. 11) that, "Progressivity refers to the tax take increasing as pure profits increase (at a more than proportional rate) which leaves marginal incentives unchanged." These statements fail to recognize that a tax levied specifically on rents would not distort incentives, regardless of whether it is progressive, proportional, or regressive. In fact, this sort of mix-up between neutrality and progressivity is replete in the literature on petroleum and minerals taxation.

\section{A Different Perspective}

The apparent confusion between neutrality and progressivity arises because of the loose terminology used to describe rent taxes. As suggested in the previous paragraph, the concept of progressivity in resource taxation seems relevant only (or mainly) in the context of the second-best optimal policy. ${ }^{10}$ In other words, overall tax regime progressivity cannot be the first-best solution to maximizing the government's revenue from its resource ownership. The first-best policy is trivial: it calls for a single tax rate on economic rent approaching 100 percent. The optimal proportional rate could be lower than 100 percent only if the government desired to leave a portion of the rent in private hands. The apparent awkwardness of this selfevident optimal policy is undoubtedly the reason why "economists who focus on tax neutrality have nothing to say about the optimal tax rate" (Lund, 2009: 297).

Progressivity becomes very relevant, however, in the presence of imperfections in the tax system. This appears to be what many economists really have in mind when they recommend tax progressivity, but they confuse progressivity of the profit-based taxes with progressivity in overall rent collection. Sumner (1978: 9), for example, argues that "the basic objection to the resource rent tax is that it cannot simultaneously provide neutrality and progressivity." However, the desire for a tax system that is both neutral and progressive is itself theoretically incoherent. If the system is designed to be truly neutral, then the tax rate should be proportional to the economic rent - that is, 100 percent. $^{11}$

\footnotetext{
${ }^{10}$ The theory of the second-best refers to the optimal policy when there are pre-existing distortions in the economy.

${ }^{11}$ Sumner notes that a resource rent tax, based on rates of return thresholds, could generate 'gold-plating' distortions and then shows how to contruct a tax on the net present value of projects, that would be both nondistortionary and progressive, thus, in effect, missing the point.
} 
Imperfections, or more precisely non-neutralities, in real world tax systems arise either as deliberate acts of policy or because the information required for implementing a tax purely on economic rent is lacking. Thus, as the literature in fact stresses, revenue maximization is typically not the only goal of tax policy. The other main objectives are to secure revenues for the government even if the project turns out to be unprofitable (i.e., the government is more riskaverse than the investors), and to obtain revenues as soon as possible (i.e., the government's discount rate is higher than the investors'). These objectives require the tax system to include regressive, non-neutral, elements, such as royalties and limitations on cost recovery. More subtly, the desire to tax rents directly is hampered by the government's inability to know the precise discount rate of the investors. This observation is what led Garnaut and Clunies Ross (1983) to recommend multiple tiers for the Resource Rent Tax based on critical values of the internal rate of return (IRR). They argued that it is better to err on the side of not discouraging marginal investments, even if this forsakes some potential rent collection. Hence, the first tier of the rent tax is designed to be conservative in the sense that the permitted rate of return is likely to be too high and the corresponding tax rate is relatively low. Higher IRR thresholds and marginal tax rates follow after the first tier, as it becomes increasingly unlikely that the projects are marginal. Moreover, the lack of a full loss offset (when a project's total cash flows are insufficient to recover costs) is itself a source of distortion in the Resource Rent Tax. The argument for a progressive Resource Rent Tax therefore lies in the imperfections of the tax itself.

A similar type of concern explains why in practice no one suggests a 100 percent tax on the observed rent. The reason is that the observed rent is not the ('true') economic rent, when there exist some 'hidden inputs' to production. In that case, taxing the observed rent is nonneutral, in contrast to a tax levied truly on economic rent. In effect, when there are hidden inputs, their costs are non-deductible and an apparent tax on economic rent is actually a tax on the quasi-rent generated by the hidden inputs. Commentators mention concerns that setting too high a tax rate on 'rent' will lead project managers to convert cash income into 'psychic income' (Kemp, 1975) or to reduce managerial 'effort' or deter innovation (Land, 2010), or to engage in abusive transfer pricing. Similarly, Osmundsen (2005) notes that multinational companies with specialized inputs must be compensated by the host country for their 'mobility rents' in order to attract them. However, these mobility rents represent the opportunity cost of applying a scarce resource to a specific project, given the option to apply it elsewhere instead. Consequently, in a proper calculation of the economic rent of the project, the value of the scarce inputs should be deducted as a cost and hence excluded from the tax base. In contrast, the 'observed rent' would typically not include such a deduction. ${ }^{12}$ Stated in terms of economic theory, all of these observations amount to denying that the observed rent is actually the economic rent and, therefore, like with any distortionary tax, the damage rises exponentially with the tax rate. In this context, clearly, the tax rate on (observed) 'rent' must be significantly less than 100 percent. It is the lack of clarity in the literature about the meaning

\footnotetext{
${ }^{12}$ In the case where the scarce input is a person, such as an exceptional manager, it may be expected that the person would capture the mobility rents in the form of a relatively higher salary; otherwise, other firms would hire the person away from the current employer. Then, the financial cost of a project that uses the person's services would include the mobility rent and the observed rent would more closely correspond to the economic rent.
} 
and measurement of rent that creates the apparent dilemma between neutrality and progressivity as criteria for tax policy.

The two reasons given above for why progressivity is meaningful only in the context of imperfections - i.e., multiple policy objectives and a lack of information for implementing the tax on rent - are really two sides of the same coin. The inherent nature of all imperfections in the tax system, whether deliberate or accidental, is that they impose a burden on a tax base that differs from the ('true') economic rent. In fact, typical tax systems can be written as a combination of a pure rent tax and a tax directly levied on an input to production (a so-called factor tax). Moreover, factor taxes are inherently regressive (or at least non-progressive). This means they increasingly miss capturing economic rent as the rent rises. This is inevitable since factor taxes are not sensitive to profit. Thus to maximize rent capture, given the regressive elements, a tax regime must add progressive elements to absorb the portion of economic rent that is left over by the regressive components. In essence, progressive tax instruments are the complements of the regressive elements of a tax regime that is designed to maximize tax revenues, subject to the constraints of achieving other goals, such as early revenues or stable revenues. Progressivity, then, is not about the overall tax regime, but about the optimal design of the complementary tax instruments. It is also important to note that taxes on factors of production, whether explicit or implicit, destroy some of the potential economic rent by distorting the firm's choice of inputs or by making marginal projects uneconomical. Thus inefficiency and regressivity go hand in hand, because the tax base for a factor tax does not coincide with economic rent. Factor taxes may achieve secondary policy goals, but they reduce the tax revenues otherwise available to the government. This fact places the tax revenue maximization objective squarely in a framework of second-best optimality.

The view presented here is not really new; it appears implicitly in other articles, especially some early ones on North Sea oil, that advocate increasing marginal tax rates on corporate profit or on other tax bases correlated with profit. The logic of the progressive rent tax suggested by Garnaut and Clunies Ross (1983) can be understood in this context. Similarly, Kemp (1975) discusses the possibilities of designing a progressive corporate profit tax by making the tax rates an increasing function of profits per barrel; or a progressive property tax based on the in-situ value of the oil fields. The purpose of Kemp's suggestions is 'efficacy in extracting rents' and he measures the efficacy by gauging the extent to which alternative packages of tax instruments drive the after-tax internal rate of return down to close to what is believed to be the minimum rate required by investors. However, subsequent writers have tended to mix up the practical need for an increasing schedule of the marginal tax rates on profits with an arguably spurious policy objective of achieving progressivity in the overall fiscal package.

The convenient terminology of 'regressivity' and 'progressivity' of fiscal instruments contains an ambiguity. Consider a gross royalty rate scheme with a progressive sliding scale. A progressive royalty can be seen as attempting to use a single instrument to achieve both the government's auxilliary objectives and maximizing rent capture. Then the lowest rate of the royalty schedule should be considered as the regressive part, there to ensure early revenues, while the remaining marginal rates should be considered as the additional rent gathering part 
of the regime. From this perspective, a progressive royalty scheme appears as a poor policy choice, since there are other far more profit-sensitive instruments available for collecting the residual rent left over from the lowest royalty rate. There is confusion in the literature over this point, precisely due to the emphasis on achieving overall progressivity as a guiding principle (see, e.g., the above quotation of Lad-Ojomo (2008/2009)). Consider now a corporate income tax. The tax falls partly on rent and partly on equity-financed capital. To the extent that the lack of a deduction for the cost of equity is due to practical concerns (e.g., the difficulty of measuring the cost of equity), it may be argued that the corporate income tax serves the primary function of maximizing tax revenues. More generally, unlike a royalty, a corporate income tax permits significant deductions for costs of production. In the context of petroleum and minerals taxation, these observations can justify an 'excess profits tax' as a progressive supplement to the regular corporate income tax.

The following sections expand on the previous remarks by analyzing a simple static model. The model serves the purpose of verifying our intuitions and uncovering additional insights. It is first shown that non-neutral taxes can be decomposed into a direct tax on rent and a regressive factor tax. Then the optimality of a progressive profit tax is analyzed in the presence of two types of tax distortions: a gross royalty on the value of production and imperfect deductibility of the costs of production. The latter may be also interpreted as an hidden or unverifiable cost, which by its very nature cannot be tax deductible.

\section{Decomposing Non-Neutral TAXes into a Rent TAX And a Factor TaX}

It is useful to show formally how a non-neutral tax can be decomposed into a factor tax and a direct tax on rent. Consider the following simple static model. An input $\gamma$ is used to produce $F(\gamma)$ units of the natural resource, with first and second derivatives $F^{\prime}>0$ and $F^{\prime \prime}<0 .{ }^{13}$ The price of the resource is $p$ and the price of the input is $c$. Hence, economic rent in this model is

$$
V(\gamma)=p F(\gamma)-c \gamma
$$

The first-order condition for rent-maximization determines the socially optimal value of the input, $\gamma^{* *}$ :

$$
p F^{\prime}\left(\gamma^{* *}\right)-c=0
$$

\section{A. Rent Tax}

A proportional tax at the rate $\rho$ imposed directly on the rent generated by the firm is neutral, because it does not alter the first-order condition for $\gamma$. Hence, the after-tax profit $\pi$ and the

\footnotetext{
${ }^{13}$ The input $\gamma$ can represent pre-production capital expenditures or ongoing variable inputs. The general point is that the firm responds to distortionary taxes by reducing its expenditures on production inputs.
} 
government's tax revenue $T$ are given, respectively, by

$$
\begin{aligned}
\pi\left(\gamma^{* *}\right) & =(1-\rho) V\left(\gamma^{* *}\right) \\
T\left(\gamma^{* *}\right) & =\rho V\left(\gamma^{* *}\right)
\end{aligned}
$$

Note that the Average Effective Tax Rate (AETR) for a proportional rent tax is constant:

$$
\operatorname{AETR}=\frac{T\left(\gamma^{* *}\right)}{V\left(\gamma^{* *}\right)}=\rho
$$

Obviously, given a fixed $\rho$, the government take is independent of the price of the resource: $d A E T R / d p=0$.

\section{B. Factor Tax}

Now consider a factor tax at the rate $\phi$ levied on the input $\gamma$. The firm's after-tax profit and the government's revenue are now

$$
\begin{aligned}
& \pi\left(\gamma^{*}\right)=V\left(\gamma^{*}\right)-\phi c \gamma^{*} \\
& T\left(\gamma^{*}\right)=
\end{aligned}
$$$$
\phi c \gamma^{*}
$$

where $\gamma^{*}$ is the solution to the firm's first-order condition,

$$
p F^{\prime}\left(\gamma^{*}\right)-(1+\phi) c=0
$$

Since the marginal product $F^{\prime}$ is a decreasing function $\left(F^{\prime \prime}<0\right)$ and $\phi>0$, it follows that $\gamma^{*}<\gamma^{* *}$ and $V\left(\gamma^{*}\right)<V\left(\gamma^{* *}\right)$. Thus, the factor tax reduces the actual rent below the potential economic rent of the project, which represents a tax distortion from the factor tax. Note that,

$$
\begin{aligned}
& \frac{\partial \gamma^{*}}{\partial \phi}=\frac{c}{p F^{\prime \prime}}<0 \\
& \frac{\partial \gamma^{*}}{\partial p}=-\frac{F^{\prime}}{p F^{\prime \prime}}>0
\end{aligned}
$$

Equation (9) says that the firm's input choice is decreasing in the factor tax rate, while (10) indicates that the input increases with the output price. The AETR in the case of a factor tax is

$$
A E T R=\frac{T\left(\gamma^{*}\right)}{V\left(\gamma^{*}\right)}=\frac{\phi c \gamma^{*}}{V\left(\gamma^{*}\right)}
$$


Consider how the AETR changes with the price of the resource:

$$
\begin{aligned}
\frac{d(A E T R)}{d p} & \equiv \frac{d\left(\frac{\phi c \gamma^{*}}{V\left(\gamma^{*}\right)}\right)}{d p}=\frac{\frac{d \gamma^{*}}{d p} \phi p c\left(F-\gamma^{*} F^{\prime}\right)-\phi c \gamma^{*} F}{V^{2}} \\
& =-\phi c\left(\frac{F F^{\prime}}{F^{\prime \prime}}-\frac{\gamma F^{\prime} F^{\prime}}{F^{\prime \prime}}+\gamma^{*} F\right) / V^{2}
\end{aligned}
$$

Let us examine (12). In the calculations of the AETR typically undertaken by project analysts, the input choices are held fixed when varying the price of output. Hence, in (12), with $d \gamma^{*} / d p=0$, it would follow immediately that the factor tax is regressive, as the AETR falls with the price of the output, as it would with the size of the economic rent. Taking the input value as fixed could correspond to a case where capital decisions have aready been sunk and there are unexpected windfall gains from price increases. However, when $d \gamma^{*} / d p>0$, the sign of $d(A E T R) / d p$ is ambiguous without further details on the production technology. Equation (13) is obtained by substituting (10) for $d \gamma^{*} / d p$ into (12). To evaluate the sign of the expression (13), consider three specific cases for $F(\gamma)$. These three production functions will be used repeatedly below to illustrate the sign value of ambiguous analytical expressions.

\section{Quadratic Production Function}

First, assume the production technology is quadratic:

$$
F(\gamma)=a \gamma-(b / 2) \gamma^{2}
$$

with $\gamma \in[0,2 a / b]$. In this case, $F^{\prime}=a-b \gamma$ and $F^{\prime \prime}=-b$ and

$$
\gamma^{*}=\frac{a}{b}-\frac{(1+\phi) c}{b p}
$$

Then (13) simplifies to the expression

$$
\frac{d\left(\frac{\phi c \gamma^{*}}{V\left(\gamma^{*}\right)}\right)}{d p}=-(1 / 2) a \phi c\left(\gamma^{*}\right)^{2} / V^{2}<0
$$

Hence, with a quadratic production function the factor tax is regressive.

\section{Logarithmic Production Function}

As a second case, consider a logarithmic production function:

$$
F(\gamma)=\ln \gamma
$$


In this case, $F^{\prime}=1 / \gamma, F^{\prime \prime}=-\left(1 / \gamma^{2}\right)$ and

$$
\gamma^{*}=\frac{p}{(1+\phi) c}
$$

Substituting the relevant expressions into (13) shows, once again, that the factor tax is regressive, since

$$
\frac{d\left(\frac{\phi c \gamma^{*}}{V\left(\gamma^{*}\right)}\right)}{d p}=-\phi c \gamma^{*} / V^{2}<0
$$

\section{Exponential Production Function}

Finally, consider an exponential production function:

$$
F(\gamma)=\gamma^{\alpha}
$$

with $0<\alpha<1, F^{\prime}=\alpha \gamma^{\alpha-1}, F^{\prime \prime}=\alpha(\alpha-1) \gamma^{\alpha-2}$ and

$$
\gamma^{*}=\left(\frac{\alpha p}{(1+\phi) c}\right)^{1 /(1-\alpha)}
$$

In this case, (13) becomes

$$
\frac{d\left(\frac{\phi c \gamma^{*}}{V\left(\gamma^{*}\right)}\right)}{d p}=-\phi c\left(\gamma^{*}\right)^{\alpha+1}\left(\frac{1}{\alpha-1}-\frac{\alpha}{\alpha-1}+1\right)=0
$$

Thus, in the exponential case, the AETR is proportional to the factor tax. However, the factor tax is never progressive in any of the cases.

Now that we have established the constancy of the AETR under a proportional rent tax and the tendency for a declining profile of the AETR under a factor tax, we turn to two non-neutral taxes commonly used in practice: a royalty and corporate profit tax. Both of these taxes are shown to be equivalent to a combination of a tax on the realized rent and a factor tax. The idea is very general and applies to many types of tax regimes.

\section{Royalties}

Consider a royalty levied at the rate $\lambda$ on the value of sales $p F(\gamma)$. In this case, the firm's after-tax profit and the government's tax revenue, respectively, are given by

$$
\begin{aligned}
& \pi(\gamma)=p F(\gamma)-c \gamma-\lambda p F(\gamma) \\
& T(\gamma)=\lambda p F(\gamma) .
\end{aligned}
$$


The firm's equilibrium after-tax profit (23) and the government's revenue (24) can be rewritten equivalently as

$$
\begin{aligned}
\pi\left(\gamma^{*}\right) & =(1-\lambda) V\left(\gamma^{*}\right)-\lambda c \gamma^{*} \\
T\left(\gamma^{*}\right) & =\lambda V\left(\gamma^{*}\right)+\lambda c \gamma^{*}
\end{aligned}
$$

Hence, the AETR is

$$
A E T R=\lambda+\frac{\lambda c \gamma^{*}}{V\left(\gamma^{*}\right)}
$$

Thus the effect of the royalty is the same as a proportional tax on rent combined with a regressive factor tax. As shown previously, the factor tax will make the overall effect regressive (or at least non-progressive). For a fixed $\lambda$, the AETR decreases in the price of the resource $p$, if the production function is quadratic or logarithmic and is constant if the production function is exponential.

\section{Profit Tax}

Suppose now that there is just a profit tax at the rate $\tau$, in which only the fraction $0<\theta<1$ of the input cost is tax deductible. ${ }^{14}$ After-tax profit and tax revenue are then

$$
\begin{aligned}
& \pi(\gamma)=p F(\gamma)-c \gamma-\tau(p F(\gamma)-\theta c \gamma) \\
& T(\gamma)=\tau(p F(\gamma)-\theta c \gamma)
\end{aligned}
$$

These expressions can again be decomposed into a rent tax and an implicit factor tax, as follows:

$$
\begin{aligned}
& \pi\left(\gamma^{*}\right)=(1-\tau) V\left(\gamma^{*}\right)-(1-\theta) \tau c \gamma^{*} \\
& T\left(\gamma^{*}\right)=\tau V\left(\gamma^{*}\right)+(1-\theta) \tau c \gamma^{*}
\end{aligned}
$$

The rent tax rate in this case is $\tau$ and the implicit factor tax rate is $(1-\theta) \tau$. For a fixed $\tau$, the AETR is again regressive (or at least non-progressive) through the factor tax equivalence:

$$
A E T R=\tau+\frac{(1-\theta) \tau c \gamma^{*}}{V\left(\gamma^{*}\right)}
$$

In summary, the analysis has shown how factor taxes are distortionary and tend toward regressivity, and that there is a theoretical equivalence between a factor tax and other forms of taxation that include the cost of an input in the tax base. Thus, a tax that is non-neutral generates a regressive component in the tax regime. In the next section, it is shown why the existence of a non-neutral, regressive tax implies, in turn, that a tax levied directly on rent must

\footnotetext{
${ }^{14}$ Note that the profit tax becomes a direct rent $\operatorname{tax}$ when $\theta=1$. In the ensuing discussion, it will be convenient to use the term 'profit tax' as a catchall expression, which can correspond, e.g., to a corporate income tax $(0<$ $\theta<1)$ or a pure rent $\operatorname{tax}(\theta=1)$.
} 
be progressive, if an objective is to maximize total tax revenue. To be clear, using the notation of the current section, we aim to show that, if an explicit or implicit partial factor tax at rate $\phi$ raises revenues of $\phi c \gamma^{*}$, then capturing the remaining rent $V\left(\gamma^{*}\right)-\phi c \gamma^{*}$ requires a progressive marginal tax rate schedule on rent or profit. More specifically, we consider the relationship between the optimal tax rate $\tau$ and the price of the resource $p$. Since $p$ is exogenous in the model, it is convenient to consider the relationship between $\tau$ and $p$, rather than between $\tau$ and $V\left(\gamma^{*}\right)$. However, as $V\left(\gamma^{*}\right)$ is increasing in $p$, the results shown imply a similar relationship between $\tau$ and $V\left(\gamma^{*}\right)$.

\section{Progressive Profit Tax Rates}

\section{A. Royalty and Profit Tax}

We turn now to the issue of the optimal degree of progressivity of the profit tax. There are two types of tax rates in the model. A royalty on the value of production is levied at the rate $0 \leq \lambda<1$ and a progressive profit tax, with a tax rate that is an increasing function of the output price $p$, is levied at the rate $0 \leq \tau(p) \leq 1$. Suppose also that a proportion $0<\theta \leq 1$ of the input cost can be deducted in the calculation of the profit tax. If $\theta=1$, there is full deductibility of costs in the profit tax and the tax becomes equivalent to a tax levied directly on economic rent. When $\theta<1$, then, as discussed in the previous section, a profit tax is simultaneously a tax on rent and an implicit factor tax. The possible lack of full deductibility of the input cost can be taken as representing two types of situations. First, there may be imperfect deductibility of observed costs by deliberate policy design. Second, the imperfect deductibility may arise because the input is not observed or imperfectly observed by the government. Thus, values of $\theta<1$ represent realistic situations where the government cannot capture 100 percent of the economic rent, because attempting to do so would exacerbate a distortionary tax on the unobserved input; indeed, in the model the firm would respond by optimally choosing $\gamma^{*}=0$ as $\tau$ approaches 1 when $\theta<1$. This latter case seems very much in the spirit of arguments for progressive taxation frequently made in the literature. In addition, let there be a fixed payment, such as a signature bonus, $B \geq 0$ (assumed to be non-deductible).

The tax revenue is

$$
\begin{aligned}
T(\gamma) & =\tau(p F(\gamma)-\theta c \gamma)+\lambda p F(\gamma)+B \\
& =(\tau+\lambda) V(\gamma)+(\lambda+(1-\theta) \tau) c \gamma+B
\end{aligned}
$$


The firm's after-tax profit is given by ${ }^{15}$

$$
\begin{aligned}
\pi(\gamma) & =V(\gamma)-T(\gamma) \\
& =p F(\gamma)-c \gamma-\tau(p)(p F(\gamma)-\theta c \gamma)-\lambda p F(\gamma)-B \\
& =(1-\tau(p)-\lambda) p F(\gamma)-(1-\theta \tau(p)) c \gamma-B
\end{aligned}
$$

\section{B. Firm's Behavior with Distortionary Taxes}

The firm observes $p$ and chooses $\gamma$ to maximize after-tax profit, given the tax rate schedule $\tau(p)$ and the exogenous values of $\lambda, \theta$ and $B$. The firm's first-order condition for profitmaximization yields the solution for $\gamma^{*}$ as a function of $p, \tau(p), \lambda$, and $\theta$ :

$$
p F^{\prime}\left(\gamma^{*}\right)=\frac{(1-\theta \tau(p)) c}{(1-\tau(p)-\lambda)}
$$

A positive value for $\gamma^{*}$ requires $\tau+\lambda<1 .{ }^{16}$ An important observation follows from (38). Even with full deductibility of $\operatorname{costs}(\theta=1)$, so that the profit tax is a tax on economic rent, the presence of royalties $(\lambda>0)$ renders the profit tax non-neutral. Similarly, if there are no royalties $(\lambda=0)$ but imperfect deductibility of $\operatorname{costs}(\theta<1)$, then again the profit tax is distortionary. Only in the case of $\lambda=0$ and $\theta=1$ is the profit tax neutral in its effect of the firm's input choice, $\gamma^{*}{ }^{17}$

Note the effects of tax and royalty rates and price on the firm's input choice $\gamma^{*}$ :

$$
\begin{aligned}
\frac{\partial \gamma^{*}}{\partial \tau} & =\frac{(1-\theta(1-\lambda)) c}{(1-\tau-\lambda)^{2} p F^{\prime \prime}}<0 \\
\frac{\partial \gamma^{*}}{\partial \lambda} & =\frac{(1-\theta \tau) c}{(1-\tau-\lambda)^{2} p F^{\prime \prime}}<0 \\
\frac{\partial \gamma^{*}}{\partial p} & =\frac{-(1-\theta \tau) c}{(1-\tau-\lambda) p^{2} F^{\prime \prime}}>0
\end{aligned}
$$

Inequalities (39)-(41) state, respectively, that the input is decreasing in the profit tax rate (if $\lambda>0$ or $\theta<1$ ), decreasing in the royalty rate, but increasing in the price of the resource.

\footnotetext{
${ }^{15}$ It is assumed for simplicity that royalties are non-deductible from the profit tax. The analysis would be qualitatively similar if royalties were tax deductible, since they would still engender a tax distortion. (Only if $\theta=1$ and $\tau=1$ would royalties be neutral if they are tax deductible.) However, when there is a tax credit for the royalty payments, applicable to the profit tax liability, then the presence of royalties would not compound the tax distortion caused by the profit tax, even when $\theta<1$.

${ }^{16}$ If there are no distortions $(\lambda=0, \theta=1)$, then $\tau=1$ as a limit value is feasible.

${ }^{17}$ The fixed payment, $B$, does not distort the choice of $\gamma$, except if it causes the firm's after-tax profit to be negative. It is assumed in that case that the project is not undertaken, i.e., $\gamma^{*}=0$ if $\pi<0$. Thus, even when $\lambda=0$ and $\theta=1$, the fixed payment is regressive and distortionary in the sense of affecting the firm's extensive margin.
} 
The second derivatives of $\gamma^{*}$ with respect to the profit tax rate are: ${ }^{18}$

$$
\begin{aligned}
\frac{\partial^{2} \gamma^{*}}{\partial \tau^{2}} & =\frac{(1-\theta(1-\lambda)) c}{(1-\tau-\lambda)^{3} p F^{\prime \prime}} \times\left(2-\frac{\left(p F^{\prime}-\theta c\right)}{p} \frac{F^{\prime \prime \prime}}{F^{\prime \prime}}\right) \\
\frac{\partial^{2} \gamma^{*}}{\partial \tau \partial p} & =-\frac{(1-\theta(1-\lambda)) c}{(1-\tau-\lambda)^{2} p^{2} F^{\prime \prime}} \times\left(1-\frac{F^{\prime} F^{\prime \prime \prime}}{\left(F^{\prime \prime}\right)^{2}}\right) \\
\frac{\partial^{2} \gamma^{*}}{\partial \tau \partial \lambda} & =\frac{(1-\theta \tau)+(1-\theta(1-\lambda)) c\left(1-\frac{F^{\prime} F^{\prime \prime \prime}}{\left(F^{\prime \prime}\right)^{2}}\right)}{(1-\tau-\lambda)^{3} p F^{\prime \prime}}
\end{aligned}
$$

where $\tau$ is the profit tax rate at the corresponding price $p$. The signs of the second derivatives (42)-(44) are in general ambiguous due to the term $F^{\prime \prime \prime}\left(\gamma^{*}\right)$. However, they can be signed for the quadratic, logarithmic, and exponential production functions considered previously. For all three production functions, $\partial^{2} \gamma^{*} / \partial \tau^{2}<0$, since $F^{\prime \prime}<0$, while $F^{\prime \prime \prime} \geq 0$ and $p F^{\prime}-\theta c>0$ (using (38)). That is, the distortion in the firm's input choice becomes more severe as the profit tax rate increases. The expression for $\partial^{2} \gamma^{*} / \partial \tau \partial p$ is positive in the case of the quadratic production function (since $F^{\prime \prime \prime}=0$ ), but it is negative in the logarithmic and exponential cases. Finally, the sign of the cross-derivative $\partial^{2} \gamma^{*} / \partial \tau \partial \lambda$ is the opposite of the sign of $\partial^{2} \gamma^{*} / \partial \tau \partial p$ and it serves as a reminder that the size of the distortion caused by one tax is not independent of the level of the other tax.

\section{Progressivity of the Profit Tax}

We now consider the optimal marginal tax rate schedule on rent or profit. To emphasize the role of the resource price, the tax revenue $T$ and economic rent $V$ will be written below explicitly as functions of $p$. In equilibrium, the rent is

$$
V(p)=p F\left(\gamma^{*}\right)-c \gamma^{*}
$$

and total tax revenue is

$$
T(p)=\tau(p)\left(p F\left(\gamma^{*}\right)-\theta c \gamma^{*}\right)+\lambda p F\left(\gamma^{*}\right)+B
$$

The firm's after-tax profit is

$$
\pi(p)=(1-\tau(p)-\lambda) p F\left(\gamma^{*}\right)-(1-\theta \tau(p)) c \gamma^{*}-B
$$

Assuming the firm shuts down (i.e., $\gamma^{*}=0$ ) if its after-tax profit is negative, the objective of the government is to maximize tax revenue, subject to the firm earning a non-negative aftertax profit. The solution to the government's revenue maximization problem generates a tax schedule $\tau(p ; \lambda, \theta, B)$ which varies with the price of the resource $p$. The constrained maxi-

${ }^{18}$ By Young's theorem, $\frac{\partial^{2} \gamma}{\partial \tau \partial p}=\frac{\partial^{2} \gamma}{\partial p \partial \tau}$ and $\frac{\partial^{2} \gamma}{\partial \tau \partial \lambda}=\frac{\partial^{2} \gamma}{\partial \lambda \partial \tau}$. 
mization problem for the government is

$$
\max _{\tau} T(p) \quad \text { subject to } T(p) \leq V(p)
$$

Either the constraint binds and $T(p)=V(p)$ or the value of $T(p)$ is maximized while $T(p)<$ $V(p)$. The latter situation would happen if the tax distortions cause a 'Laffer curve' such that tax revenues decline before all of the rent is captured by the government. We shall examine the cases of a binding constraint and a non-binding constraint separately.

Figure 1 and Figure 2 can be used to illustrate the binding $(T=V)$ and non-binding $(T<$ $V)$ constraints, respectively. Both figures graph the total tax revenue $(T)$ and the size of the economic rent $(V)$ against the profit tax rate $(\tau)$ in the presence of a distortion. The size of the rent is declining in the tax rate, because of the interaction between the tax distortions and the profit tax. If there were no distortions $(\lambda=0, \theta=1)$, then the profit tax is a 'pure' rent tax. Then the economic rent would be independent of $\tau$ and attain its maximum potential value for the project. The maximum achievable rent is depicted in Figures 1 and 2 as $V^{* *}$. Given the distortions associated with $\lambda>0$ or $\theta<1$, tax revenue initially rises with $\tau$, but eventually declines, which is a Laffer curve. In Figure 1, tax revenue is maximized at the intersection of the tax revenue curve and the economic rent curve. This is the case of a binding constraint. The government captures all of the realized economic rent, although the size of this rent is below the potential economic rent of the project, due to the tax distortions. In Figure 2, the peak of the Laffer curve occurs at a value of $\tau$ that is less than the point at which the revenue and rent curves intersect. This illustrates the case of the non-binding constraint, in which the government does not capture all of the realized rent.

\section{Binding Constraint: $T(p)=V(p)$}

The main result to be demonstrated is that $d \tau^{*}(p) / d p>0$ whenever $\lambda>0$ or $\theta<1$. Let us first consider the case where the profit constraint is binding:

$$
T\left(\gamma^{*}\right)=V\left(\gamma^{*}\right)
$$

which can be written as ${ }^{19}$

$$
\tau\left(p F\left(\gamma^{*}\right)-\theta c \gamma^{*}\right)+\lambda p F\left(\gamma^{*}\right)+B=p F\left(\gamma^{*}\right)-c \gamma^{*}
$$

or, equivalently,

$$
(1-\tau-\lambda) p F\left(\gamma^{*}\right)=(1-\theta \tau) c \gamma^{*}+B
$$

\footnotetext{
${ }^{19}$ The profit tax rate $\tau(p)$ varies with $p$, but for notational ease, explicit reference to $p$ is omitted in writing $\tau$ in the following expressions. However, there is a different solution for $\tau$ at each price $p$.
} 


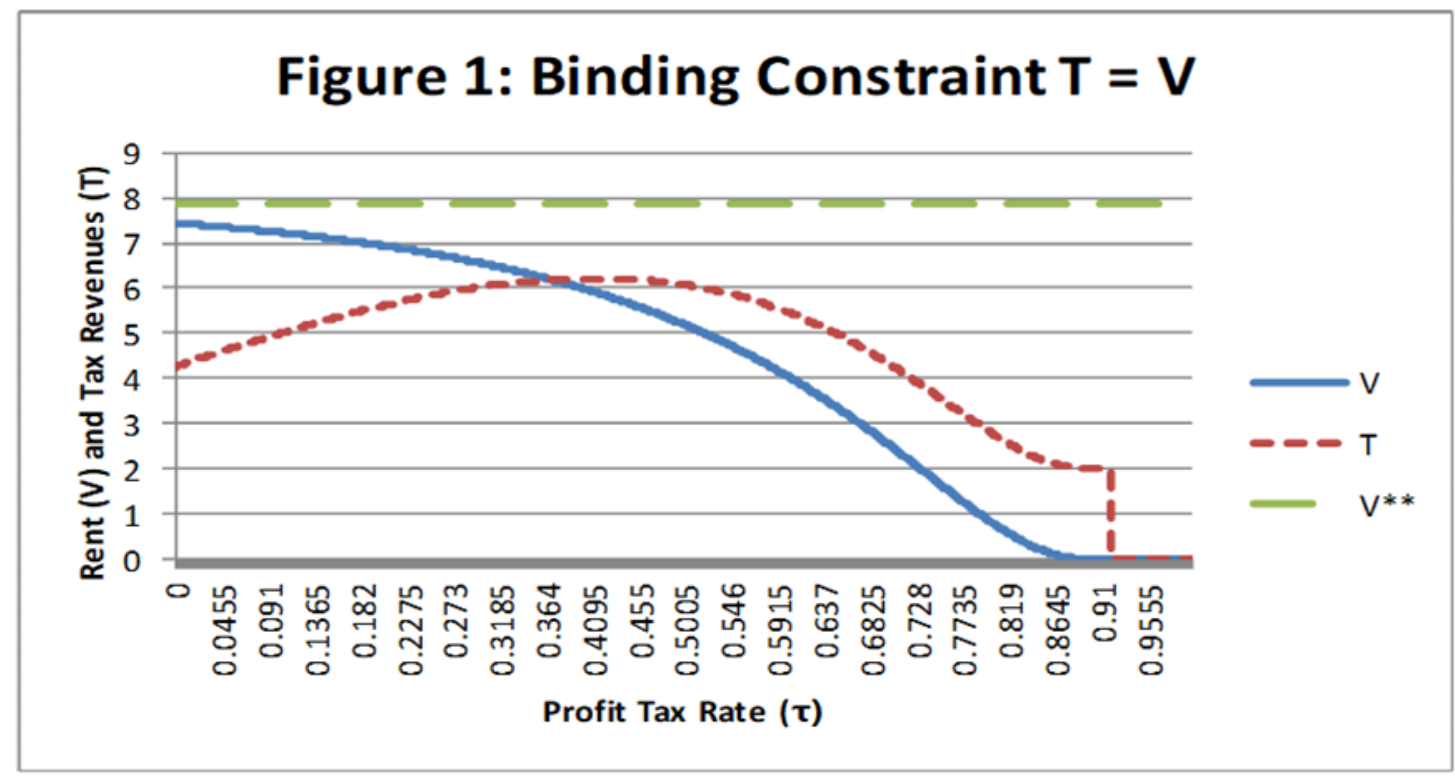

In the simulation, $\mathrm{F}(\gamma)=\gamma^{0.8}, \mathrm{p}=6, \mathrm{c}=3, \mathrm{~B}=2, \lambda=.08, \theta=.9, \tau^{*}=.370$.

The case depicted occurs when the constraint $\mathrm{T} \leq \mathrm{V}$ is binding.

The curves correspond to the maximum potential rent, $\mathrm{V}^{* *}$, the realized rent, $\mathrm{V}$, and government revenues, $\mathrm{T}$.

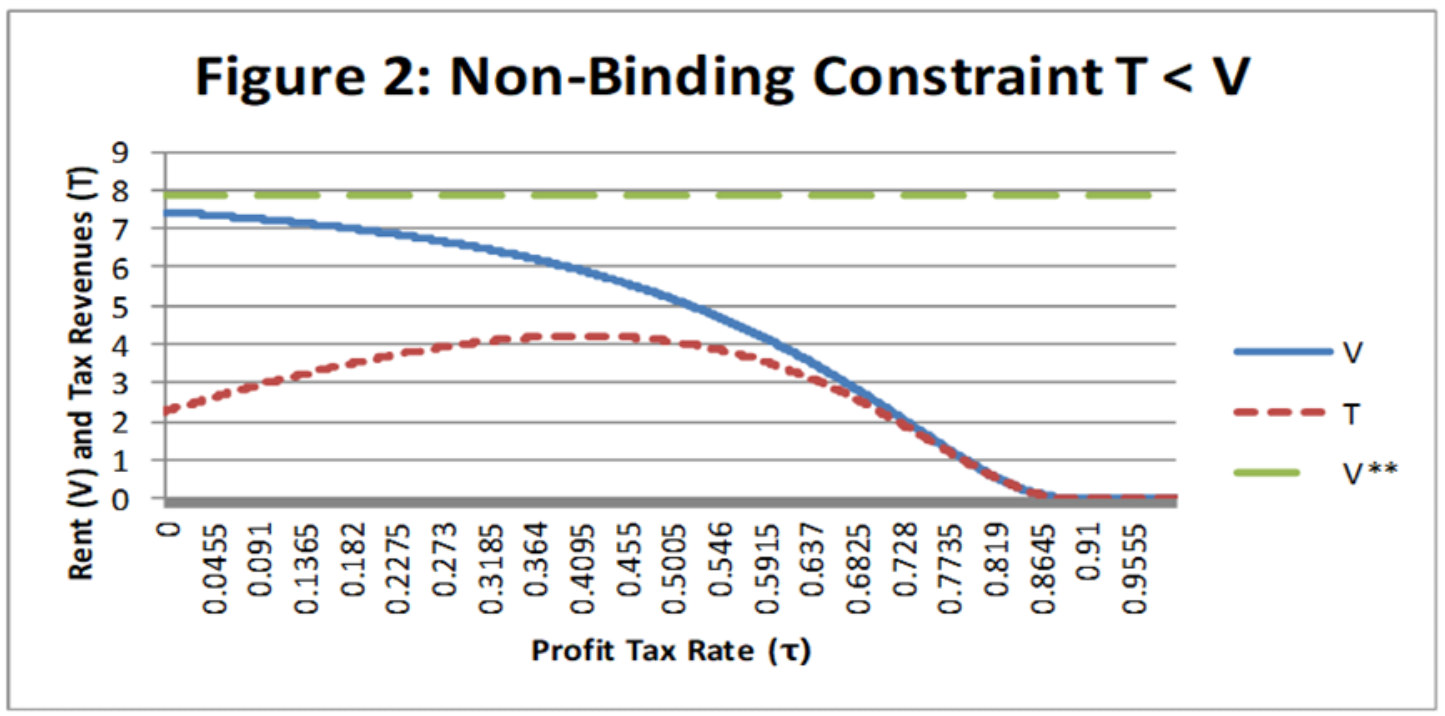

In the simulation, $\mathrm{F}(\gamma)=\gamma^{0.8}, \mathrm{p}=6, \mathrm{c}=3, \mathrm{~B}=0, \lambda=.08, \theta=.9, \tau^{*}=.414$.

The case depicted occurs when the constraint $\mathrm{T} \leq \mathrm{V}$ is non-binding.

The curves correspond to the maximum potential rent, $\mathrm{V}^{* *}$,

the realized rent, $\mathrm{V}$, and government revenues, $\mathrm{T}$. 
Equation (51) implicitly defines the optimal profit tax rate $\tau$ as a function of the parameters $\lambda, \theta, B$, and $p .^{20}$ To see how the optimal tax rate $\tau$ varies with the price $p$, take a total differential of (51) with respect to $\tau$ and $p$. Using the equations (39) and (41) to substitute for $\partial \gamma^{*} / \partial \tau<0$ and $\partial \gamma^{*} / \partial p>0$, and applying the envelope theorem, the result is

$$
\frac{d \tau}{d p}=\frac{(1-\tau-\lambda) F\left(\gamma^{*}\right)}{p F\left(\gamma^{*}\right)-\theta c \gamma^{*}}>0
$$

where the inequality follows from the fact that the denominator is positive, since $V\left(\gamma^{*}\right)=$ $p F\left(\gamma^{*}\right)-c \gamma^{*}>0$ and $\theta \leq 1$, while the numerator is positive, since $\tau+\lambda<1$ for $\gamma^{*}>0$. Hence, the optimal profit tax rate exhibits marginal tax rate progressivity. If, however, $\lambda=0$ and $\theta=1$, then the optimal tax rate is simply $\tau=1$ and hence $d \tau / d p=0$, as expected.

Consider how the degree of progressivity is affected by the fixed payment (say, a non-deductible signature bonus), $B$. Then, differentiating (52) with respect to $B$ gives

$$
\begin{aligned}
\frac{d^{2} \tau}{d p d B} & =\frac{(1-\tau-\lambda) \theta c}{\left(p F-\theta c \gamma^{*}\right)^{2}}\left(F-\gamma^{*} F^{\prime}\right) \times\left[\frac{\partial \gamma^{*}}{\partial B}+\frac{\partial \gamma^{*}}{\partial \tau} \frac{\partial \tau}{\partial B}\right] \\
& -\frac{\left(p F-\theta c \gamma^{*}\right) F}{\left(p F-\theta c \gamma^{*}\right)^{2}} \times \frac{\partial \tau}{\partial B}
\end{aligned}
$$

Since the fixed payment does not affect the firm's first-order condition (38), $\partial \gamma^{*} / \partial B=0$ in (53). The term $\frac{\partial \gamma^{*}}{\partial \tau} \frac{\partial \tau}{\partial B}$ arises because an increase in the fixed payment necessitates a reduction in the profit tax, in order to preserve the equality in (51). That is, from differentiating (51) with respect to $\tau$ and $B$, holding $p$ constant, we obtain, after simplifications, $d \tau / d B=$ $-1 /\left(p F-\theta c \gamma^{*}\right)<0$; thus, as the fixed payment increases, the profit tax rate must fall, at every price, so that the total fiscal payments do not exceed the available rent. Furthermore, since $\partial \gamma^{*} / \partial \tau<0$ from (39), the sign of $d^{2} \tau / d p d B$ in (53)-(54) is unambiguously positive if $\left(F-\gamma^{*} F^{\prime}\right) \geq 0$. The term $\left(F-\gamma^{*} F^{\prime}\right)$ is positive for the quadratic and exponential production functions; it is positive for the logarithmic production function if $\gamma^{*}>e \approx 2.178$. These observations suggest that the degree of progressivity tends to increase with the size of the fixed payment.

Now consider the effect on the degree of profit tax progressivity, as the royalty rate increases. As in the case of the fixed payment, an exogenous increase in the royalty rate will break the constraint (51), unless the profit tax rate $\tau$ adjusts downward to compensate. The required adjustment is obtained by differentiating (51) with respect to $\tau$ and $\lambda$, holding $p$ constant. The result is $d \tau / d \lambda=-p F /\left(\left(p F-\theta c \gamma^{*}\right)<0\right.$. Then, differentiating (52) with respect to the

\footnotetext{
${ }^{20}$ Note that, when $\lambda=0$ and $\theta=1$ but $0<B<V(p)$, then there is a maximum feasible value of $\tau(p)$; beyond that point, $T(p)>V(p)$ and the firm would shut down to avoid earning a negative after-tax profit.
} 
royalty rate and manipulating terms gives

$$
\begin{aligned}
\frac{d^{2} \tau}{d p d \lambda} & =-\frac{F}{\left(p F-\theta c \gamma^{*}\right)} \times\left(1+\frac{d \tau}{d \lambda}\right) \\
& +\frac{(1-\tau-\lambda) \theta c\left(F-\gamma^{*} F^{\prime}\right)}{\left(p F-\theta c \gamma^{*}\right)^{2}} \times\left[\frac{\partial \gamma^{*}}{\partial \lambda}+\frac{\partial \gamma}{\partial \tau} \frac{d \tau}{d \lambda}\right]
\end{aligned}
$$

Substituting the expression above for $d \tau / d \lambda$ and the partial derivatives of $\gamma^{*}$ using (39) and (40), results in the final expression:

$$
\frac{d^{2} \tau}{d p d \lambda}=\frac{\theta c \gamma^{*} F}{\left(p F-\theta c \gamma^{*}\right)^{2}}+\frac{(\theta c)^{2}\left(F-\gamma^{*} F^{\prime}\right)^{2}}{\left(p F-\theta c \gamma^{*}\right)^{3} F^{\prime \prime}}
$$

The first term on the right side of (57) is positive, suggesting greater progressivity, but the second term is negative, since $F^{\prime \prime}<0$. Consequently, the overall effect of increasing the royalty rate on the optimal degree of progressivity of the profit tax is ambiguous. The difference between raising the royalty rate, $\lambda$, versus increasing the fixed payment, $B$, examined previously in (53)-(54), is that, unlike with the fixed payment, the royalty rate interacts with the profit tax rate in distorting the input choice, $\gamma^{*}$. However, numerical simulations of the model suggest that with the quadratic, logarithmic, and exponential production functions, the degree of progressivity of the profit tax increases when the royalty rate is raised. Analogous results can be obtained with respect to the implication of imperfect deductibility of costs in the profit tax base $(\theta<1)$ on the degree of progressivity of the profit tax. Thus, a greater presence of regressive elements will tend to increase the rate of progressivity of the profit tax, while also lowering the level of the tax schedule to accommodate the higher royalty rate.

\section{Numerical Simulations of the Model with a Binding Constraint}

The results are illustrated with numerical simulations of the model, using a logarithmic production function. Figures 3 and 4 provide results of the model with the binding constraint $(T(p)=V(p))$ at two different prices, holding the royalty rate fixed at $\lambda=.05$. As $p$ rises from 6 to 7 , the optimal tax rate rises from $\tau=.618$ to $\tau=.695$, for an increase of $\Delta \tau=.077$. The calculations are repeated for a higher royalty rate, $\lambda=.08$, in Figures 5 and 6 . Then, as the price rises from 6 to 7 , the optimal tax rate rises from $\tau=.564$ to $\tau=.646$, for an increase of $\Delta \tau=.082$. Thus, while at each royalty rate the tax rate $\tau(p)$ is progressive, it is more progressive at the higher royalty rate.

\section{E. Non-Binding Constraint: $T(p)<V(p)$}

Now consider the case where the concavity of the tax revenue function $T$ is such that it reaches a peak before revenues capture all of the available rent $V$. Thus the constraint on the government's maximization problem is non-binding. Differentiating the right-hand side of $T(p)$ in 


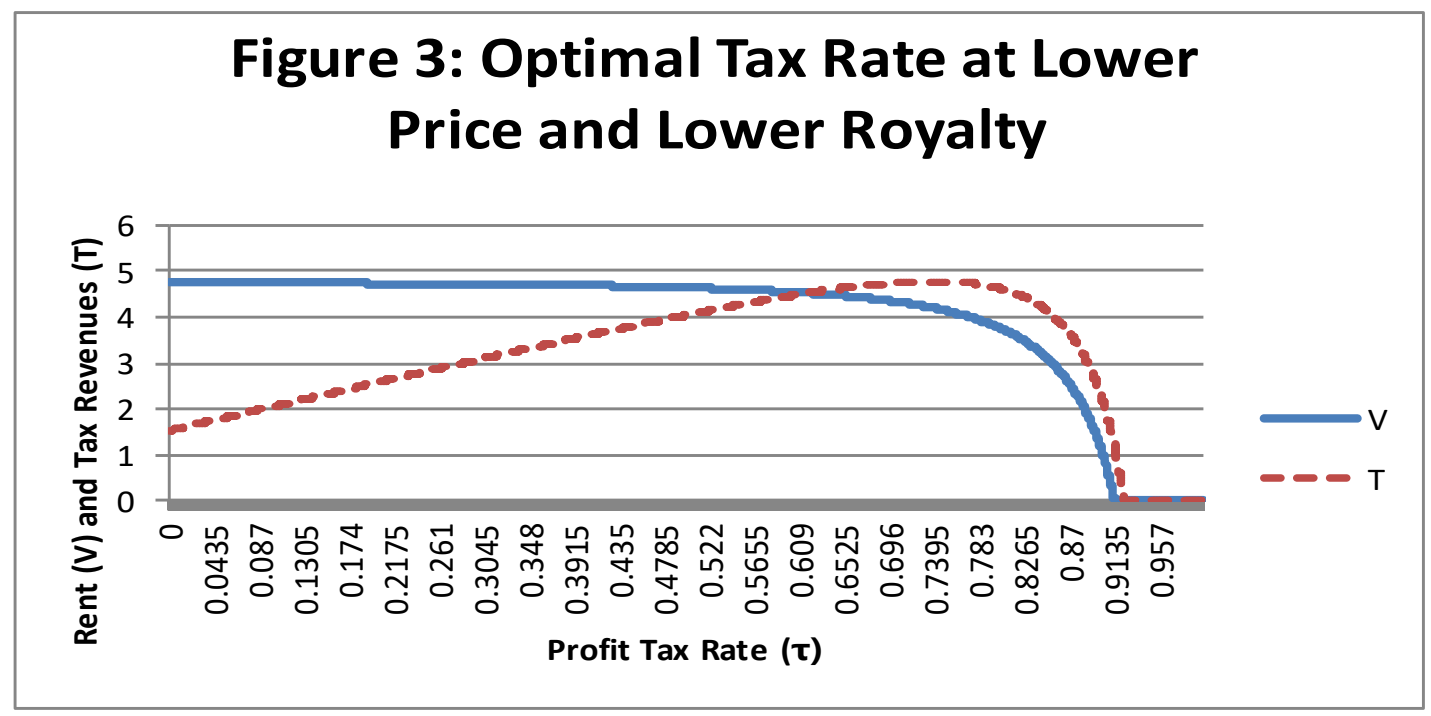

In the simulation, $\mathrm{F}(\gamma)=\ln (\gamma), \mathrm{p}=6, \mathrm{c}=1, \mathrm{~B}=1, \lambda=.05, \theta=.9, \tau^{*}=.618$

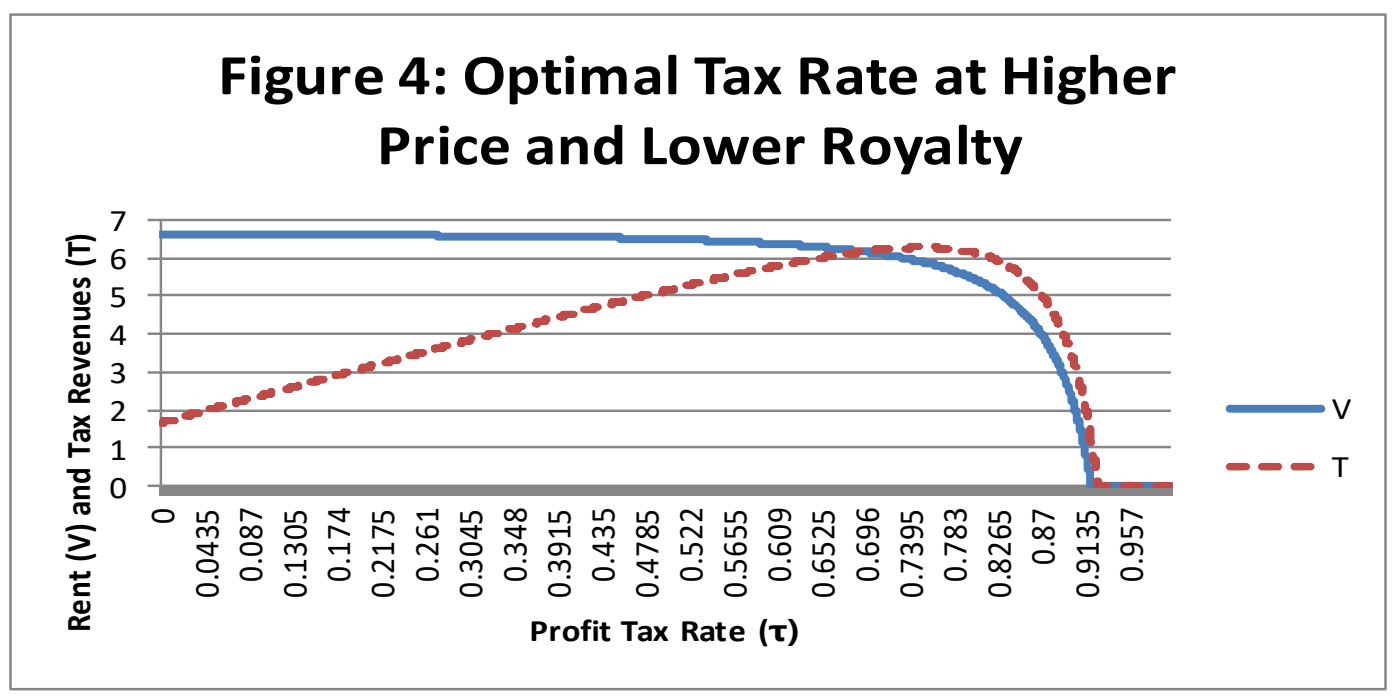

In the simulation, $\mathrm{F}(\gamma)=\ln (\gamma), \mathrm{p}=7, \mathrm{c}=1, \mathrm{~B}=1, \lambda=.05, \theta=.9, \tau^{*}=.695$ 
Figure 5: Optimal Tax Rate at Lower Price and Higher Royalty

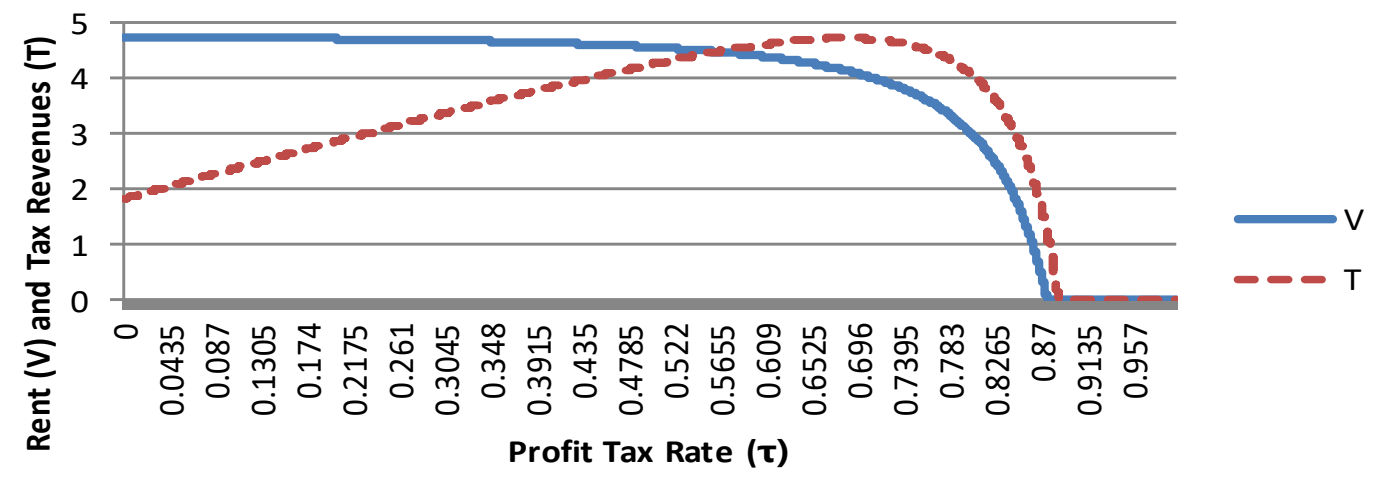

In the simulation, $\mathrm{F}(\gamma)=\ln (\gamma), \mathrm{p}=6, \mathrm{c}=1, \mathrm{~B}=1, \lambda=.08, \theta=.9, \tau^{*}=.564$

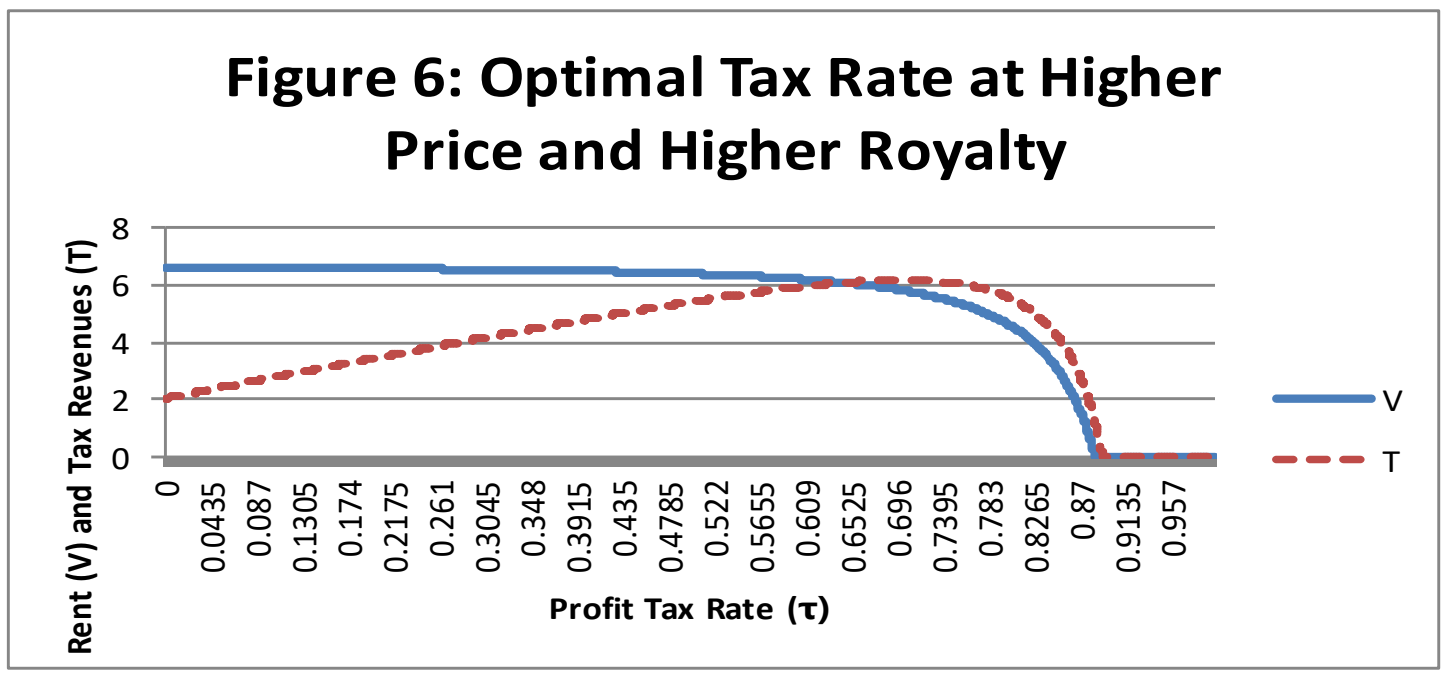

In the simulation, $\mathrm{F}(\gamma)=\ln (\gamma), \mathrm{p}=7, \mathrm{c}=1, \mathrm{~B}=1, \lambda=.08, \theta=.9, \tau^{*}=.646$ 
(46) and setting the result equal to zero gives

$$
\frac{d T}{d \tau}=\left(p F-\theta c \gamma^{*}\right)+\tau\left(p F^{\prime}-\theta c\right) \frac{\partial \gamma^{*}}{\partial \tau}+\lambda p F^{\prime} \frac{\partial \gamma^{*}}{\partial \tau}=0
$$

Since $\tau$ must be set optimally by the government for each price, the comparative statics calculation treats the government's first-order condition (58) as an identity. The shape of the optimal tax schedule $\tau(p)$ is then characterized by taking the total derivative of (58) with respect to $p$ and $\tau$ (for fixed $\lambda, \theta$ and $B$ ) to obtain an expression for $d \tau / d p$. After simplifying terms, the result is 21

$$
\begin{gathered}
d p\left[F+\left(p F^{\prime}-\theta c\right) \frac{\partial \gamma^{*}}{\partial p}+\tau\left(p F^{\prime}-\theta c\right) \frac{\partial^{2} \gamma^{*}}{\partial \tau \partial p}+\lambda p F^{\prime} \frac{\partial^{2} \gamma^{*}}{\partial \tau \partial p}\right] \\
=-d \tau\left[\begin{array}{c}
2\left(p F^{\prime}-\theta c\right) \frac{\partial \gamma^{*}}{\partial \tau}+(\tau+\lambda) p F^{\prime \prime}\left(\frac{\partial \gamma^{*}}{\partial \tau}\right)^{2} \\
+\tau\left(p F^{\prime}-\theta c\right) \frac{\partial^{2} \gamma^{*}}{\partial \tau^{2}}+\lambda p F^{\prime} \frac{\partial^{2} \gamma^{*}}{\partial \tau^{2}}
\end{array}\right]
\end{gathered}
$$

where the various partial derivatives were calculated previously in equations (39)-(43). In (60), all of the terms in the braces are negative (assuming $F^{\prime \prime \prime} \geq 0$, which is the case with the illustrative production functions). The only source of ambiguity in the sign of (59) stems from the sign of $\frac{\partial^{2} \gamma^{*}}{\partial \tau \partial p}$ (see (43)); the term is positive in the case of a quadratic production function. In that case, $d \tau / d p>0$. That is, when the peak of the Laffer curve occurs before taxes capture all of the available rent, the profit tax exhibits marginal tax rate progression. Furthermore, simulations indicate that the profit tax is progressive in the case of the logarithmic prduction function and proportional in the case of the exponential production function, for these Laffer curve scenarios.

\section{F. Implications for Average Tax Rate Progressivity}

The previous section has shown that the second-best optimal profit tax should exhibit marginal tax rate progressivity. What about average tax rate progressivity-i.e., does the government take rise with the price of the resource? Clearly, in the case of the binding constraint, $T=V$, government take is 100 percent at every price, by construction. However, it is useful to consider how government revenue changes with price, as a share of the observed rent, $\hat{V}$, rather than the realized rent, $V$. The oberved rent refers to an over-estimate of the economic rent, due to the omission of a portion of the costs in the calculation of the rent. As discussed previously, this omission can correspond to unobserved factors of production from the perspective of the government. Thus, $\hat{V}=p F\left(\gamma^{*}\right)-\theta c \gamma^{*}$, where $\theta<1$. Figure 7 graphs two curves, based on simulations of the model with an exponential production function. The dashed curve is the AETR when the denominator is the observed rent, $\hat{V}$ and the constraint is binding, $T=V$. It can be seen that government revenues are rising, as a share of the observed

\footnotetext{
${ }^{21}$ The simplification of terms makes use of the fact that $F^{\prime}+p F^{\prime \prime} \frac{\partial \gamma^{*}}{\partial p}=0$ from differentiating the firm's firstorder condition (38) with respect to $p$.
} 
rent, as the price rises. In the non-binding case, where government revenue is maximized before full rent capture, the AETR can be calculated at the different prices, based on the ratio of revenues to the realized value of rent, $V\left(\gamma^{*}(p, \tau, \lambda, \theta)\right)$. This is also graphed in Figure 7 . In the simulation of the model, government take is found to be constant as the price of the resource changes, and hence also constant with the size of the realized rent. The horizontal AETR curve is a byproduct of the second-best optimal profit tax rate progressivity, rather than a deliberate design feature of the optimal fiscal regime. ${ }^{22}$

\section{Practical Implications}

The analysis of the simple model in this paper suggests that the evaluation of tax policy for petroleum and mineral resources depends on four general points. The first is that the existence and magnitude of regressive components in the tax regime must be justified by the government's auxilliary objectives. The second point is that the overall tax regime's ability to capture rent and to promote political stability should be determined by the size of the overall AETR, not its progressivity. Third, the profit-sensitive tax instrument should be designed progressively, in the sense of the tax rate on profit rising with the value of economic rent, or with a correlate of rent, such as the resource price. This can be achieved, for example, by having more than one tier in a resource rent tax. It does not necessarily follow that the profile of the AETR, that is, government take, should itself be progressive. Indeed, an approximate rule-ofthumb for policy guidance would be that the AETR should be broadly constant across a range of profitability outcomes, with the progressive elements inversely related to the regressive elements in the fiscal regime. Finally, in designing a fiscal regime, it is important to recognize that the distortionary nature of regressive taxes causes even the taxes levied directly on rent to no longer be neutral. For example, a resource rent tax can compound the disincentives for investment created by a high royalty rate on gross revenues. Thus, while greater reliance on regressive instruments generally implies greater progressivity of the profit-sensitive instruments, the precise relationship is complicated, due to the second-best policy considerations.

To detect visually whether the progressive elements are appropriately progressive, an AETR graph for the progressive and regressive fiscal instruments could be plotted separately. The more regressive are the distorting elements of the fiscal regime, the more progressive should the AETR curve be for the profit-sensitive elements. At the same time, the general position of the AETR curve for the progressive elements must be lowered to accommodate high levels of the regressive instruments. This graphical analysis could be done in an approximate way by classifying the major tax/royalty instruments in the fiscal regime as relatively progressive or regressive, based on whether their primary purpose is rent collection, versus a secondary goal, such as early revenues or revenue stability. In the case of production sharing contracts, profit oil shares interact with cost oil limits. One approach to separating the regressive and progressive components of a production sharing contract is to simulate the model without a

\footnotetext{
${ }^{22}$ The horizontal AETR is a feature of an exponential production function. The AETR is rising in simulations with a quadratic production function.
} 


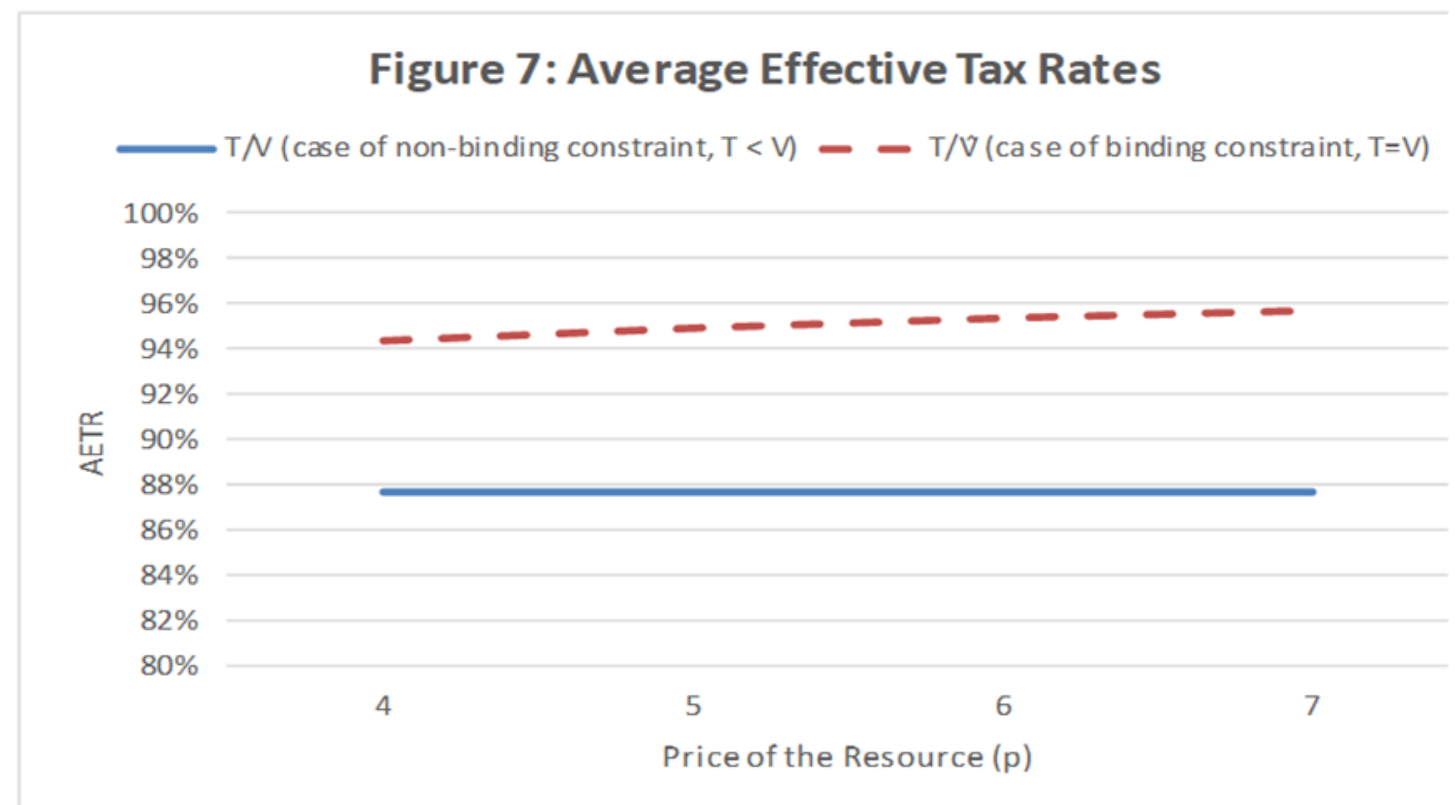

The graph depicts the size of the 'government take' or AETR as the price of the resour increases from 4 to 7 . The dashed line is for the situation where tax revenue, $\mathrm{T}$, exactly equals the realized rent from the project, $V$, which is the 'binding constraint' case. Since this would make the AETR $=\mathrm{T} / \mathrm{V}$ equal to one at every price, the AETR is plotted, inst against the 'observed rent' of the project, $\hat{V}$, defined as the (mis-estimated) rent that would appear if only $\theta=90 \%$ of project costs are recognized and are tax deductible. The solid curve displays the AETR in the non-binding constraint case, where $T$ is maximizec at a profit tax rate that does not capture all of the economic rent, due to a 'Laffer curve effect caused by the tax distortions. The simulations are based on an exponential production function, $\mathrm{F}(\gamma)=\gamma^{4}$, with $\mathrm{p}$ varying from 4 to $7, \mathrm{c}=3, \lambda=.02, \theta=.9$, with $\mathrm{B}=1$ in the binding constraint case and $\mathrm{B}=0$ in the non-binding constraint case. 
cost oil limit and then to resimulate it with the cost oil limit. The revenues raised implictly by the regressive cost oil limit is the difference between the second and first simulations. ${ }^{23}$ Furthermore, the discussion suggests that the concept of tax buoyancy, or an elasticity, can serve as a diagnostic tool for whether the progressive instruments are capturing the economic rent left over by the regressive instruments. Specifically, starting at the breakeven price, the elasticity of total government revenue from the project, with respect to the economic rent of the project, should be close to one. In this way, for example, a 10 percent increase in the NPV of the project would be expected to generate a 10 percent increase in the NPV of government revenue, signifying that the progressive tax instruments have captured the additional rent, generated by, say, an increase in the resource price. However, in applying this elasticity as a diagnostic tool, it must be borne in mind that non-deductible costs or other sources of tax distortions will tend to destroy some of the potential economic of the project.

From the perspective described in this paper, certain types of fiscal instruments make little sense. In particular, the use of royalties with increasing marginal tax rates (say, as a function of oil prices), which is a policy used by some governments, is, in effect, using one instrument to achieve two distinct policy objectives: obtaining a steady or early flow of revenues and maximizing rent capture. Such a policy is likely to create large distortions similar to a progressive factor tax. It would be better to set a constant royalty rate at a modest level and to capture rent with a progressive tax on rent or (as a next best alternative) on corporate income. The progressive tax rates can be calibrated for various price scenarios, so as to deliver a target value of the investors' after-tax internal rate of return. ${ }^{24}$ Furthermore, providing a tax credit for royalties, to be applied against the rent tax, with an uplift to account for the time value of money, would largely offset the distortion caused by royalties and would reduce the case for marginal progressivity of the rent tax, while justifying a higher level of government take.

Further work is needed to test a progressive rent schedule in a dynamic environment, where the price of the resource changes period-by-period. One possibility for implementing a rent tax in a dynamic setting is Sumner's (1978) suggestion of a progressive tax rate schedule applied each period on the present value of a project's lifetime accumulative net cash flows, while providing tax credits for the taxes paid in the previous periods. In this way, taxes are paid sequentially, on the ex post value of the resource. As it would be impractical to fine tune the tax schedule for each project, a generic regime could to be selected based on the performance of the fiscal regime for a portfolio of projects.

\footnotetext{
${ }^{23}$ Note, however, that even with a cost oil limit of $100 \%$ of production, the fact that cost oil does not include an uplift for the time value of money on initial investments will impart a regressive aspect to the profit oil mechanism, even with progressive tranches of government profit oil shares.

${ }^{24}$ As the required IRR is likely to vary across projects and types of investors, the calibration of the fiscal regime can only be done in an approximative way, with suitable sensitivity analysis across project characteristics.
} 


\section{Conclusions}

This paper has provided a critical review of the literature on the progressive taxation of petroleum and minerals, in order to suggest that the literature over-emphasizes an ideal of a progressive overall fiscal package. Instead, it may be more appropriate for the government to receive a fixed proportion of the rent, albeit at a suitably high level. It is the progressive components of the fiscal regime, such as a resource rent tax, a corporate income tax, or the government's share of profit oil, each designed with multiple tiers, that allow this to occur, by complementing the regressive components. The regressive components may occur by design, as in when the government uses them to address objectives other than revenue maximization, such as achieving early revenues with a royalty. The regressive elements may also occur 'by accident,' when there exist intangible forms of costs, such as managerial effort, which are unobserved by the government and hence are not deductible from the tax base. The regressive elements distort the firm's choice of inputs and reduce the size of the realized economic rent below its potential value. In this second-best policy environment, the government, as resource owner, should aim to capture as much of the economic rent as it can. Ideally it would capture 100 percent of it through its portfolio of progressive and regressive taxes. However, it must also be recognized that unobserved and non-deductible costs imply that the observed tax base for profit-sensitive or rent-based taxes may overstate the true size of the realized economic rent. For this reason, taxing nearly 100 percent of the observed economic rent is generally inappropriate in practice. This perspective on the purpose and measurement of tax progressivity was illustrated with a simple theoretical model, in which a second-best optimal tax schedule for a rent tax or profit tax was analyzed, taking into account the inevitable existence of tax distortions in fiscal regimes for natural resources.

One way to calibrate the schedule of rent-based progressive tax rates is to determine what the tax rate would need to be at different prices of the resource, given the anticipated production and cost profiles of resource projects, such that the investors' after-tax rate of return is held constant, at a rate deemed to be acceptable to investors. Then, all unanticipated increases in economic rent due, e.g., to price increases, would accrue to the government, implying an elasticity of revenue with respect to rent equal to one. However, the tax schedule need not be expressed directly as a function of prices, but could, instead, be made to depend on commonly used profit indicators, such as the R-factor. Indeed, if projects vary substantially in terms of costs and production, then it may be best to set the tax rate schedule as a function of a profit indicator, rather than price. Setting the tax rates directly as a function of price can prevent 'gold-plating' activities, whereby firms increase expenditures inefficiently, simply to reduce the indication of profitability. However, firms can still attempt to manipulate the fiscal regime under price-based tax schedules, but only to the extent that they can time their expenditures, so that they occur when prices are perceived to be relatively high. Finally, tax credits, rather than tax deductions, for royalties and signature bonuses would help reduce the distortions caused by the major regressive elements of a fiscal regime. This would reduce the need for progressivity in marginal tax rates, and likely raise the overall level of government take. 


\section{REFERENCES}

[1] Boadway, Robin and Michael and Keen (2010) Theoretical Perspectives on Resource Tax Design. Chapter 2 in Daniel et al. (2010).

[2] Caldor, Jack (2010) Resource Tax Administration: the Implications of Alternative Policy Choices. Chapter 11 in Daniel et al. (2010).

[3] Daniel, Philip, Brenton Goldsworthy, Wojciech Malizewnski, Diego Mesa Puyo, and Alistair Watson (2010) Evaluating Fiscal Regimes for Resource Projects: an Example from Oil Development. Chapter 7 in Daniel et al. (2010).

[4] Daniel, Philip, Michael Keen, and Charles McPherson (2010) The Taxation of Petroleum and Minerals: Principles, Problems and Practice (New York: Routledge).

[5] Garnaut, Ross, and Ian Clunies Ross (1983) Taxation of Mineral Rents (Oxford: Clarendon Press).

[6] Hann, D. and C. Rowland (1986) UK Oil Taxation: Failings and Reform, Surrey Energy Economics Centre, University of Surrey, Discussion Paper no. 32.

[7] Keen, Michael, Peter Mullins, Oana Luca, and Roderick Eggert (2014) Israel: Reviewing the Fiscal Regime for Mining. International Monetary Fund, Fiscal Affairs Department.

[8] Kemp, Alexander G. (1975) Fiscal Policy and the Profitability of North Sea Oil Exploitation, Scottish Journal of Political Economy 22 (3): 237-257.

[9] Lad-Ojomo, Olatokunbo (2008/2009) What is the Role and Challenges of Progressive Taxation in Achieving Stability and Equitable Distribution of Oil Profits? CEPMLP Annual Review, Volume 12, Article 26 (Centre for Energy, Petroleum and Mineral Law and Policy, University of Dundee).

[10] Land, Bryan C. (2010) Resource Rent Taxes: a Reappraisal. Chapter 8 in Daniel et al. (2010).

[11] Luca, Oana, and Diego Mesa Puyo (2016) Fiscal Analysis of Resource Industries (FARI) Methodology, Technical Notes and Manuals, International Monetary Fund, Fiscal Affairs Department.

[12] Lund, Diderik (2009) Rent Taxation for Non-Renewable Resources, Annual Review of Resource Economics 1: 287-308.

[13] Nakhle, Carole (2004) Petroleum Taxation: A Critical Evaluation with Special Application to the UK Continental Shelf, $\mathrm{PhD}$ dissertation, University of Surrey.

[14] Osmundsen, Petter (2005) Optimal Petroleum Taxation Subject to Mobility and Information Constraints. In S. Glomsrod and P. Osmundsen (eds.), Petroleum Industry Regulation within Stable States (New York: Ashgate).

[15] Osmundsen, Petter (2010) Time Inconsistency in Petroleum Taxation: Lessons from Norway. Chapter 15 in Daniel et al. (2010). 
[16] Sumner, M.T. (1978) Progressive Taxation of Natural Resource Rents, The Manchester School: 1-16. 